\title{
A retrospective study on treatment of moderate cervicomental laxity with subdermal monopolar radiofrequency with real-time monitoring
}

\author{
Kar Wai Phoebe Lam, MBChB, MRCS, PgDipSEM, DPD, MScDPD \\ Perfect Skin Solution, Kowloon, Hong Kong
}

\begin{abstract}
Subdermal monopolar radiofrequency (RF) redefines jawline by delivering controlled thermal energy that induced soft tissue contraction. However, the type of candidates best suited for this treatment has not been determined. A retrospective analysis of the treatment results and satisfaction, at 6 weeks and 3 months, in 15 female patients, aged 34 to 77 years, with mild to moderate skin laxity (Submental Skin Laxity Grading [SMSLG], 1-3) and submental fat (SMF) (Clinician rating-SMF-Rating Scale [CR-SMF-RS], 1-3), and a Subject Self Rating Scale (SSRS) $\leq 2$. They received ThermiRF to either jowl and neck or neck only, in a single clinic, between the period of October 2017 to July 2018 . The probe treatment temperature was set and maintained between $52^{\circ} \mathrm{C}$ to $65^{\circ} \mathrm{C}$ whereas the epidermal temperature was targeted around $42^{\circ} \mathrm{C}$ to $43^{\circ} \mathrm{C}$. All patients with SMSLG 2 to 3 , reported at least 1 grade SMSLG response with a mean change of 1.23 of CR-SMF-RS and mean change of 3.08 of SSRS. None of the patients experienced a burn or erythema following treatment. Transient swelling, nodule and mild numbness following ThermiRF procedure has been reported but all resolved completely with time. All reported GAIS $\geq 3$ and $46.7 \%$ reported a Global Aesthetic Improvement Scale (GAIS) score of 5, i.e. optimal results by 3 months. Therefore, according to treatment results those with good to at least moderate skin laxity (SMSLG, 2-3), mild to moderate SMF (CR-SMF, 1-3) and absent of platysmal pathology reported at least a one-grade improvement on SMSLG and CR-SMF-RS within 3 months of ThermiRF treatment.

Level of Evidence: IV
\end{abstract}

Keywords: cervicomental; skin laxity; skin tightening; submental fat; thermiRF; thermogenesis

\section{Introduction}

Although non-invasive skin-tightening procedures have greater acceptance and more popular among patients, the ultimate aesthetic outcome is relatively modest compared of traditional face-lift surgery [1]. Minimally invasive subdermal ThermiRF (Thermal Aesthetics, Irving, TX, USA) may be an alternative option for redefining jawline in healthy patients with mild to moderate skin laxity but without cosmetic defects (e.g., vertical fibrous bands, significant drooping of redundant neck) necessary for surgical correction. Furthermore, neck rejuvenation treatments that primarily modify dermal collagen structure can only bring about two-dimensional horizontal tightening of the skin surface, for which are incapable of supporting its underlying muscle and soft tissue ptosis. A three-dimensional simultaneous contraction of layers of soft tissue, on the other hand, is mandatory for effective skin and soft tissue tightening. $[2,3]$ The strongest contraction response observed was when

Received August 30, 2018; Revised November 30, 2018; Accepted December 13, 2018

Corresponding author: Kar Wai Phoebe Lam

E-mail: drlamkarwai@gmail.com, ORCID: https://orcid.org/0000-0002-3237-3229

This is an Open Access article distributed under the terms of the Creative Commons Attribution Non-Commercial License (http://creativecommons.org/licenses/by-nc/4.0), which permits unrestricted non-commercial use, distribution, and reproduction in any medium, provided the original work is properly cited.

Copyright (c) 2018 Korean Society of Korean Cosmetic Surgery and Medicine (KSKCS \& KCCS). 
Clinician Rating-Submental fat-Rating Scale

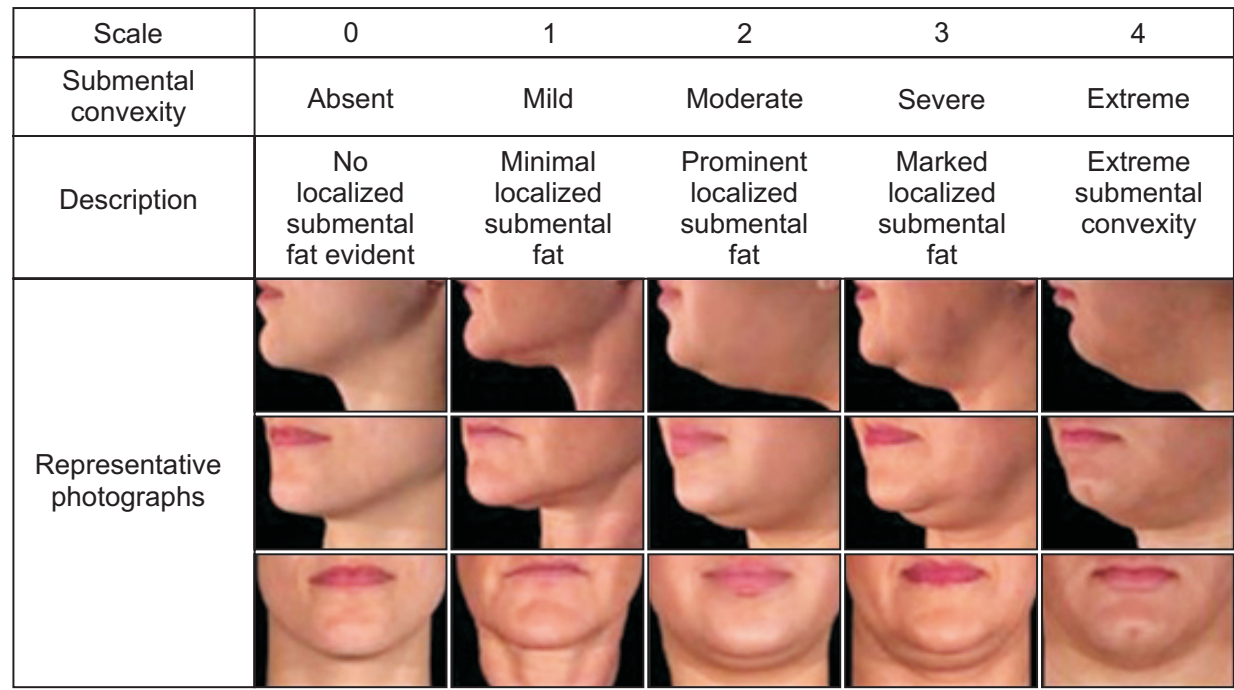

Submental Skin laxity grading scale

\begin{tabular}{|c|cccc|}
\hline Scale & 1 & 2 & 3 & 4 \\
\hline Skin laxity & None & Mild & Moderate & Severe \\
\hline Description & $\begin{array}{c}\text { None or minimal } \\
\text { superficial wrinkles }\end{array}$ & $\begin{array}{c}\text { Mild superficial } \\
\text { wrinkles }\end{array}$ & $\begin{array}{c}\text { Moderate superficial } \\
\text { wrinkles }\end{array}$ & $\begin{array}{c}\text { Superficial } \\
\text { wrinkling present, } \\
\text { may be marked }\end{array}$ \\
\hline $\begin{array}{c}\text { Representative } \\
\text { photographs }\end{array}$ & & & &
\end{tabular}

Subject Self-Rating Scale

The patient will be asked to respond to the question below. No photographs or reference to previous ratings or evaluations will be used.

Baseline: Considering your appearance in association with your face and chin, how satisfied do you feel with your appearance at the present time?

0 -Extremely dissatisfied

1-Dissatisfied

2-Slightly dissatisfied

3-Neither satisfied nor dissatisfied

4-Slightly satisfied

5-Satisfied

6-Extremely satisfied

Postbaseline: Considering your appearance in association with your face and chin, how satisfied do you feel with your appearance at the present time whether or not in your judgment it is due entirely to treatment with ThermiRF?

0 -Extremely dissatisfied

1-Dissatisfied

2-Slightly dissatisfied

3-Neither satisfied nor dissatisfied

4-Slightly satisfied

5-Satisfied

6-Extremely satisfied

Global Aesthetic Improvement Scale

\begin{tabular}{lll}
\hline \multicolumn{1}{c}{ Degree } & \multicolumn{1}{c}{ Description } \\
\hline 1 & Exceptional improvement & Excellent corrective result \\
2 & Very improved patient & Marked improvement of the appearance, but not completely optimal \\
3 & Improved patient & Improvement of the appearance, better compared with the initial condition, but a touch-up is advised \\
4 & Unaltered patient & The appearance substantially remains the same compared with the original condition \\
5 & Worsened patient & The appearance has worsened compared with the original condition
\end{tabular}

Fig. 1. Assessment grading scales [9]. 
threshold thermal energy delivered to the adipose tissues containing both the septal connective tissues and reticular collagen fibers $[2,4,5]$.

The wound-healing process commences as threshold heat energy is delivered to the dermis. Heat induces collagen coagulation in target tissue and tissue contraction occurs with mild healing responses that continue during the cooling stage of treatment within the targeted region. This will be followed by regeneration of new collagen and elastin over the next few months [6]. Under optimal conditions, with real-time temperature monitoring, the zone of inflammation (tissue injury) can be modified and constrained, resulting in only tissue devoid of an inner zone of tissue necrosis, yet, the ultimate result of controlled skin tightening. In contrast, an uncontrolled and prolonged tissue over-heating will create a full-thickness necrosis with inevitable epidermal skin injuries, visible scarring, and ulcers in consequence of the inflammatory reaction [7].

Choosing the right patient is crucial in the determination of success of treatment. Unfortunately, neither is there a universally accepted standard nor a proper definition of skin laxity in the neck; thus, words such as sagging, laxity, and tissue ptosis are customarily used, and interpretations predominantly depend on our perceptive understanding of such terms $[5,8]$. Standardized photonumeric grading systems (Fig. 1) [9] for the evaluation of submental fat (SMF) (Clinician-Reported Submental Fat Rating Scale [CR-SMF-RS]) and skin laxity (Submental Skin Laxity Grading [SMSLG]), both of which are easily reproducible with good intra- and interrater reliability, had been used in the assessments. Other parameters, such as patient satisfaction with the appearance of their face/chin based on the Self-Satisfaction Rating Scale (SSRS) and Global Aesthetic Improvement Scale (GAIS) were also used.

This retrospective study reviewed the results of the use of minimally invasive, subdermal RF in patients with mild to moderate skin laxity and SMF for tightening of loose cervical skin.

\section{Case report}

All 15 patients were female with age ranging from 34 to 77 years and skin types I to IV. Only patients with mild to moderate SMF (CR-SMF-RS, 1-3) and mild to moderate skin laxity (SMSLG, 1-3), no prior SMF intervention (e.g., liposuction, surgery, or lipolytic agent use), absent of platysmal pathology and appearance considered undesirable (SSRS $\leq 2$ ) who have also received ThermiRF were included in the analysis (Table 1).

Prior to procedure, the marginal mandibular nerve, in all 15 patients, was mapped out subcutaneously with a nerve stimulator before the procedure, and the neck skin was prewarmed to $37^{\circ} \mathrm{C}$.

Target treatment temperature was set at $52^{\circ} \mathrm{C}$ to $55^{\circ} \mathrm{C}$ (both superficial and deep) for those with CR-SMF-RS $\leq 2$; whereas for those with CR-SMF-RS $\geq 2$, ThermiRF probe temperature was set between $52^{\circ} \mathrm{C}$ and $55^{\circ} \mathrm{C}$ (superficial) and between $55^{\circ} \mathrm{C}$ and $70^{\circ} \mathrm{C}$ (deep). The device was equipped with a temperature sensor that initiated an automatic feedback loop to monitor and maintain subdermal tissue temperature. Epidermal skin temperature was monitored and maintained between $42^{\circ} \mathrm{C}$ and $46^{\circ} \mathrm{C}$ during treatment to ensure skin tightening can be achieved without causing epidermal skin injury.

Three treatment entry points (retro-auricular) were created, using a 16-G needle, on the left, right, and apex of the submental triangle. A blunt 10-cm-long, 18-G percutaneous treatment probe was inserted at an angle nearly parallel to the dermal plane, and about $80 \mathrm{ml}$ of preheated $\left(37^{\circ} \mathrm{C}\right)$ tumescent solution, containing premixed $1 \%$ lidocaine and epinephrine, was infiltrated into the treatment area. After the area has been adequately numbed, RF energy was delivered from the distal end of the treatment probe. The treatment probe was inserted into these entry points sequentially, guided at a cautious manner, sliding slowly from lateral to medial, in a point-to-point fashion, until the clinical endpoint has been reached in all premarked grids within the treatment area. All patients were discharged after the procedure with oral analgesics and were only required simple compressive dressing for 5 to 7 days.

The total treatment time, for all patients, starting from prepar-

Table 1. Patient characteristics

\begin{tabular}{cccc}
\hline Patient & Age & Neck $^{\text {a) }}$ & Face $^{\text {a) }}$ \\
\hline 1 & 38 & 1 & 1 \\
2 & 54 & 1 & 1 \\
3 & 34 & 1 & 1 \\
4 & 61 & 1 & None \\
\hline 5 & 54 & 1 & None \\
6 & 47 & 1 & 1 \\
\hline 7 & 54 & 1 & None \\
\hline 8 & 37 & 1 & 1 \\
\hline 9 & 58 & 1 & 1 \\
\hline 10 & 58 & 1 & 1 \\
\hline 11 & 77 & 1 & 1 \\
12 & 69 & 1 & 1 \\
13 & 58 & 1 & 1 \\
14 & 77 & 1 & 1 \\
\hline 15 & 68 & 1 & 1 \\
\hline
\end{tabular}

a) Treatment area. 
ing and draping, administration of anesthesia, and RF energy, for the jowl and neck, ranged between 29 to 55 minutes. None suffered skin burn or erythema following treatment. Of 15 patients, 13 (86.7\%) developed swelling within the treated area but all completely resolved within 4 to 6 weeks following treatment. Two patients (11.1\%) complained of painless palpable nodules, and 3 of 18 patients (16.7\%) had a mild submental/neck numbness following treatment. These side effects were transient and completely resolved conservatively with time ( $<4$ weeks). All patients were followed for at least 3 months after treatment.

\section{Conclusion}

Real-time temperature monitoring that allows a safe delivery of targeted treatment temperature necessary for collagen co- agulation $\left(55^{\circ} \mathrm{C}-70^{\circ} \mathrm{C}\right)[10,11]$ and induce apoptosis in adipocytes (at least $70^{\circ} \mathrm{C}$ for 1 second) [12-14]. Since the relationship between epidermal and subdermal temperature is not strongly linear dependent, therefore, synchronized thermoregulation is important in the delivery of a safe maximal subdermal therapeutic thermal energy and minimization of risks of skin injuries [15].

Apart from those with SMSLG grade 1 at the beginning of the treatment, all patients (SMSLG, 2-3) showed at least one grade improvement from baseline and one to two grade improvement of CR-SMF-RS. All patients believed that they had improved from baseline (GAIS, 3-5). Seven patients (46.7\%) reported that they had achieved significant improvement (GAIS, 5), and the remaining patients also improved. Moreover, about $26.7 \%$ (4/15, GAIS 3$)$ of patients felt that a touch-up was indicated at 3

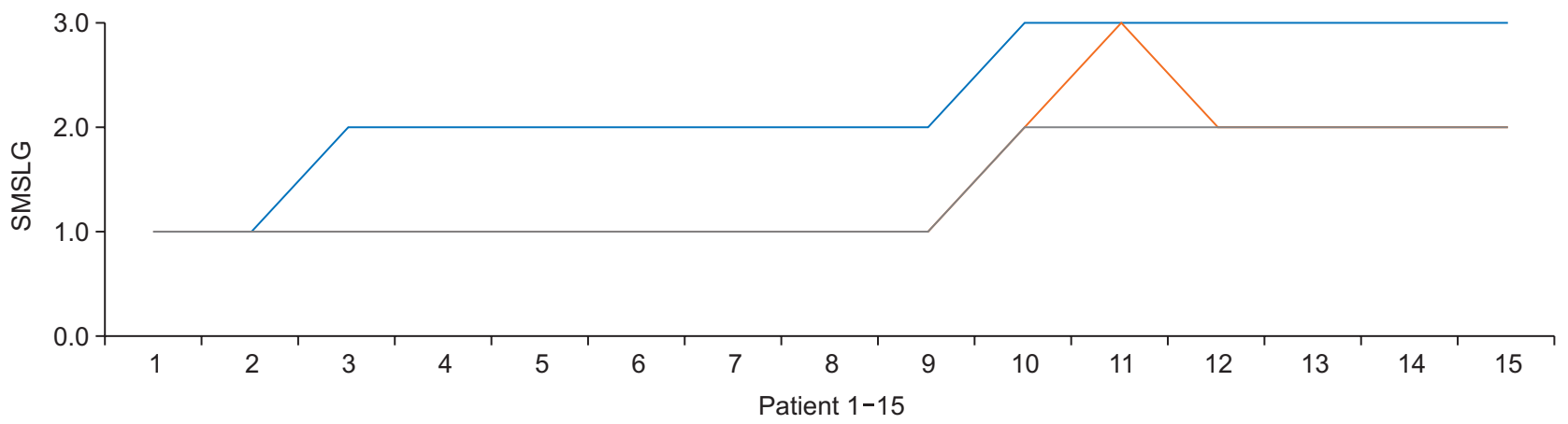

\begin{tabular}{|c|c|c|c|c|c|c|c|c|c|c|c|c|c|c|c|}
\hline SMSLG & 1 & 2 & 3 & 4 & 5 & 6 & 7 & 8 & 9 & 10 & 11 & 12 & 13 & 14 & 15 \\
\hline - Before & 1 & 1 & 2 & 2 & 2 & 2 & 2 & 2 & 2 & 3 & 3 & 3 & 3 & 3 & 3 \\
\hline - 6 weeks & 1 & 1 & 1 & 1 & 1 & 1 & 1 & 1 & 1 & 2 & 3 & 2 & 2 & 2 & 2 \\
\hline-3 months & 1 & 1 & 1 & 1 & 1 & 1 & 1 & 1 & 1 & 2 & 2 & 2 & 2 & 2 & 2 \\
\hline
\end{tabular}

Fig. 2. Submental Skin Laxity Grading (SMSLG) for 15 patients (before 6 weeks and 3 months).

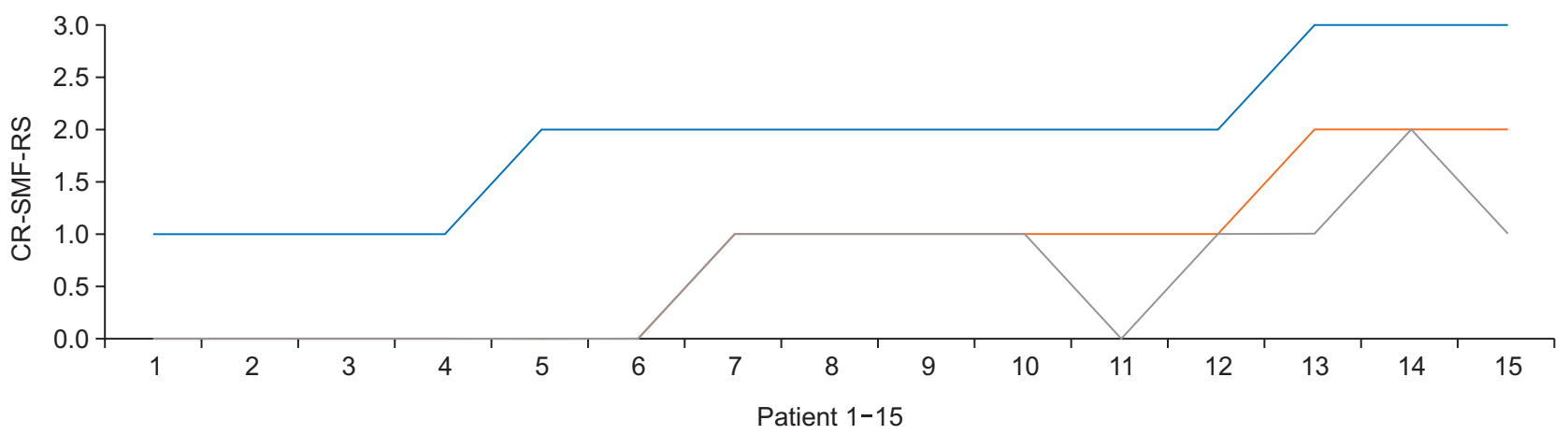

\begin{tabular}{|c|c|c|c|c|c|c|c|c|c|c|c|c|c|c|c|}
\hline CR-SMF-RS & 1 & 2 & 3 & 4 & 5 & 6 & 7 & 8 & 9 & 10 & 11 & 12 & 13 & 14 & 15 \\
\hline - Before & 1 & 1 & 1 & 1 & 2 & 2 & 2 & 2 & 2 & 2 & 2 & 2 & 3 & 3 & 3 \\
\hline - 6 weeks & 0 & 0 & 0 & 0 & 0 & 0 & 1 & 1 & 1 & 1 & 1 & 1 & 2 & 2 & 2 \\
\hline-3 months & 0 & 0 & 0 & 0 & 0 & 0 & 1 & 1 & 1 & 1 & 0 & 1 & 1 & 2 & 1 \\
\hline
\end{tabular}

Fig. 3. Clinician Rating-Submental Fat-Rating Scale (CR-SMF-RS) before 6 weeks and 3 months for 15 patients. 
months (Fig. 2, 3).

Thus, subdermal monopolar RF appears safe and effective means of submental recontouring of the neck by achieve disruption of fat volume and skin tightening of the face, neck, and jawline simultaneously. Treatment results demonstrated a high satisfaction level (GAIS, 3-5) within 3 months in patients with moderate skin laxity (SMSLG, 1-3) and SMF (CR-SMF-RS).

However, the skin within the cervicomental region is less contractile compared to those in other parts of the body, and patients should have realistic expectations of the treatment results. The development of local adverse effects (e.g., swelling, edema, erythema) is also directly related to acute inflammation arising from adipocytolytic procedures, and during adipocytolysis, all stages of inflammation are activated, either through proinflammatory cytokine or release of catecholamines, intensified by necrosis with ensuing lysis of membranes and cell death. Thus, adverse effects and symptoms (e.g., pain, discomfort, numbness, bruising) related to inflammatory healing wound responses during or after treatment are inevitable but usually resolve without significant consequences [8]. Collagen deposition following wound healing will contribute to the shrinkage of the treated area and skin tightening. Inherent skin elasticity is an important determining factor when selecting treatment procedure and governing the treatment success in restoring an appealing jawline.

Despite greater evidence [2,16-18] to support the use of energy-assisted liposuction in the cervicofacial region in their achieving of a greater extent of tissue remodeling, skin retraction, and contraction, this type of treatment should only be recommended in patients with mild skin laxity. Since secondary skin retraction is a major determinant of treatment results and cervicomental skin is far less contractile compared to those in other areas of body, therefore, overaggressive energy-assisted skin tightening with significant defatting within the subcutaneous layer will exacerbate skin redundancy in those with moderate to severe skin laxity; therefore, should be avoided in patients with pre-existing compromised skin elasticity.

For devices that rely on thermogenesis, the overall effectiveness depends on the total amount of heat energy, above-threshold temperature, and transfer to the target tissue [11]. Vigilant monitoring of treatment temperature is vital in safety and treatment success. Ongoing evolution in technologies gives rise to a variety of newer-generation energy-assisted devices that can produce much greater selectivity of target tissue, and moderation of the degree of inflammation may alleviate discomfort following the procedure and reduce unwarranted tissue damage [7].

\section{Acknowledgemen}

I am thankful for Rachelle Goering, who supported us with her expertise in the past 2 years. She has proof-reading the article and in that line improved the manuscript significantly.

\section{Conflicts of interest}

The author has nothing to disclose.

\section{References}

1. Northington M. Patient selection for skin-tightening procedures. J Cosmet Dermatol 2014;13:208-11.

2. Blugerman G, Paul MD, Schavelzon D, Mulholland RS, Sandhoffer M, Lisborg P, et al. Radio-frequency assisted liposuction (RFAL). In: Serdev N, editor. Advanced techniques in liposuction and fat transfer. London: InTech; 2011.

3. Paul M, Blugerman G, Kreindel M, Mulholland RS. Threedimensional radiofrequency tissue tightening: a proposed mechanism and applications for body contouring. Aesthetic Plast Surg 2011;35:87-95.

4. Key DJ. Integration of thermal imaging with subsurface radiofrequency thermistor heating for the purpose of skin tightening and contour improvement: a retrospective review of clinical efficacy. J Drugs Dermatol 2014;13:1485-9.

5. Badin AZ, Moraes LM, Gondek L, Chiaratti MG, Canta L. Laser lipolysis: flaccidity under control. Aesthetic Plast Surg 2002;26:335-9.

6. Sadick N. Tissue tightening technologies: fact or fiction. Aesthet Surg J 2008;28:180-8.

7. Fedok FG, Kellman RM. Controversies in facial plastic surgery. Facial Plast Surg Clin North Am 2018;26:xi-xii.

8. Kinney BM, Andriessen A, DiBernardo BE, Bloom J, Branson $\mathrm{DF}$, Gentile $\mathrm{RD}$, et al. Use of a controlled subdermal radio frequency thermistor for treating the aging neck: consensus recommendations. J Cosmet Laser Ther 2017;19:444-50.

9. Kythera Biopharmaceuticals. ATX-101 (deoxycholic acid) injection. FDA advisory advisory committee briefing materials: available for public release. Westlake Village, CA: Kythera Biopharmaceuticals, 2015.

10. Lin SJ, Hsiao CY, Sun Y, Lo W, Lin WC, Jan GJ, et al. Monitoring the thermally induced structural transitions of collagen by use of second-harmonic generation microscopy. Opt Lett 2005;30:622-4.

11. Ruiz-Esparza J, Gomez JB. The medical face lift: a nonin- 
vasive, nonsurgical approach to tissue tightening in facial skin using nonablative radiofrequency. Dermatol Surg 2003;29:325-32; discussion 332.

12. Ferguson J. Effects of subdermal monopolar RF energy on abdominoplasty flaps. J Drugs Dermatol 2016;15:55-8.

13. Hayashi K, Thabit G 3rd, Massa KL, Bogdanske JJ, Cooley AJ, Orwin JF, et al. The effect of thermal heating on the length and histologic properties of the glenohumeral joint capsule. Am J Sports Med 1997;25:107-12.

14. Vangsness CT Jr, Mitchell W 3rd, Nimni M, Erlich M, Saadat V, Schmotzer H. Collagen shortening. An experimental approach with heat. Clin Orthop Relat Res 1997;(337):267-71.

15. Key DJ. Comprehensive thermoregulation for the purpose of skin tightening using a novel radiofrequency treatment device: a preliminary report. J Drugs Dermatol 2014;13;185-9.

16. Jewell ML, Fodor PB, de Souza Pinto EB, Al Shammari MA. Clinical application of VASER--assisted lipoplasty: a pilot clinical study. Aesthet Surg J 2002;22:131-46.

17. Coleman WP III, Brody HJ, Narins RS, Moy RL, Hanke CW, Lillis PL, et al. Update from the ultrasonic liposuction task force of the American Society for Dermatologic Surgery. Dermatol Surg 1997;23:211-4.

18. Ahn DH, Mulholland RS, Duncan D, Paul M. Non-excisional face and neck tightening using a novel subdermal radiofrequency thermo-coagulative device. J Cosmet Dermatol Sci Appl 2011;1:141-6. 